\title{
Prevalence and Risk Factors for Clinical Attachment Loss in Adult Yemenis: A Community-Based Study in the City of Dhamar
}

\author{
Abdullah G. Amran 1, *, Mohammed N. Alhajj ${ }^{2}$, Adnan N. Amran ${ }^{3}$ \\ ${ }^{1}$ Department of Periodontology, Faculty of Dentistry, Thamar University, Dhamar, Yemen \\ ${ }^{2}$ Department of Prosthodontics, Faculty of Dentistry, Thamar University, Dhamar, Yemen \\ ${ }^{3}$ Faculty of Dentistry, Thamar University, Dhamar, Yemen
}

Email address:

drimran2006@yahoo.com (A. G. Amran)

${ }^{*}$ Corresponding author

\section{To cite this article:}

Abdullah G. Amran, Mohammed N. Alhajj, Adnan N. Amran. Prevalence and Risk Factors for Clinical Attachment Loss in Adult Yemenis: A Community-Based Study in the City of Dhamar. American Journal of Health Research. Vol. 4, No. 3, 2016, pp. 56-61.

doi: 10.11648/j.ajhr.20160403.14

Received: April 19, 2016; Accepted: April 28, 2016; Published: May 14, 2016

\begin{abstract}
This paper is aimed to estimate the prevalence and extent of periodontal clinical attachment loss and the possible related risk factors in adult Yemeni population. The study sample composed of 884 adult subjects (496 males and 388 females) aged $\geq 25$ years old. Clinical examination of CAL was performed on six sites for each tooth. Prevalence and severity of CAL and the relationship with the risk variables were assessed. Chi-squared and multiple regression tests were used with significant

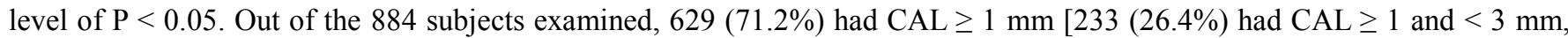
$214(24.2 \%)$ had $\mathrm{CAL} \geq 3$ and $<5 \mathrm{~mm}$, and $182(20.6 \%)$ had CAL $\geq 5 \mathrm{~mm}$ ]. Age, gender, tooth brushing, Khat chewing, smoking, plaque deposits, and calculus accumulation were associated significantly with CAL $(\mathrm{P}<0.05)$. In this study population, a high prevalence of CAL $\geq 5 \mathrm{~mm}$ was observed. Bad habits and poor oral hygiene showed strong association with the periodontal clinical attachment loss.
\end{abstract}

Keywords: Periodontal Attachment Loss, Risk Factors, Yemenis, Periodontitis

\section{Introduction}

Periodontitis is a chronic inflammatory disease of the supporting tissues around the teeth caused by dental plaque infection which is considered the major etiologic factor in pathogenesis of periodontitis. The bacteria in subgingival biofilms, with numerous other species, embed and extend apically leading to host-immune response to the bacterial plaque infection which has been implicated as a key factor in determining the extent and severity of periodontitis $[1,2]$. As a result of an immune reaction, there will be a production of cytokines array and other inflammatory mediators which cause tissue damage resulting in periodontal pockets formation, destruction of the alveolar bone and attachment loss [2]. The severity of periodontal diseases, which varies over time, depends on the quantity and quality of the biofilm and the presence of modifying factors which affect the permanence of plaque [3]. Clinical Attachment Loss (CAL) is one of the important clinical parameters which provide an indication of the degree of remaining tooth support. It occurs through the destruction of the periodontal ligament and its adjacent alveolar bone leading subsequently to gingival recession and pathologic periodontal probing depth. Therefore, the severity of periodontal disease can be estimated by the degree of CAL [4-6]. The clinical diagnosis of periodontitis is based on the measurement of presence and extent of periodontal pockets, loss of clinical attachment, pattern and extent of alveolar bone loss, or a combination of these means [7]. The measurement of CAL can be obtained by measuring the distance from the cemento-enamel junction (CEJ) down to the lowest point at the bottom of the pathological periodontal pocket using a graduated periodontal probe $[4,5]$. Although periodontal disease primarily occurs due to dental biofilms infection, it may be attributed to other risk factors such 
as age, sex, inheritance, plaque and calculus accumulation, habits (such as: smoking, khat chewing, faulty brushing technique), and iatrogenic factors [8, 9]. Prevalence of periodontitis in Arab countries ranged from $0.0 \%$ to $54.6 \%$. However, most published surveys describing oral health status, including periodontal diseases, in Arab populations have been carried out in schoolchildren and adolescents [10, 11]. Even though some studies reported that the prevalence of periodontal disease among Yemeni population is higher compared to other countries $[9,12]$, there is still a considerable lack of data regarding the prevalence of CAL in the target population. This cross-sectional study was aimed to estimate the prevalence and some possible risk factors of CAL among adult population in Dhamar City, Yemen.

\section{Material and Methods}

A cross- sectional study was conducted on adult Yemeni population randomly selected from the patients attending the learning dental hospital of the faculty of dentistry in Dhamar city seeking for dental treatment and check-up from November 2014 to April 2015. The study sample comprised of 884 adult subjects (496 males and 388 females) aged $\geq 25$ years old. The study was approved by Research and Ethics Committee, Faculty of Dentistry, University of Thamar. All participants were informed about the aim of the study and a signed informed consent was obtained. To avoid confounding factors, the following exclusion criteria were applied: 1) Systemic diseases (e.g.: diabetes mellitus, organs transplantation, and hypertension), 2) Malignant tumors including oral cavity cancer, 3) Wearing removable or fixed prosthesis or orthodontic appliance, 4) Edentulousness (full missing of teeth), and 5) Pregnant women. Data was collected by interview and clinical examination

1). Interview: The data were recorded in a special questionnaire designed to include the important information that would help to detect the correlation between clinical attachment loss (CAL) and some risk factors as age, gender, plaque accumulation, calculus deposits, as well as tooth brushing, smoking, and khat chewing habits.

2). Clinical examination: The clinical examination was carried out by the one author (Amran AG). All permanent fully erupted teeth, excluding the third molars, were examined. Plaque index, calculus index, pocket depth, and gingival recession, were measured by using a dental mirror, dental explorer and $0.4 \mathrm{~mm}$ periodontal probe (Hu-friedy's WHO-style probe, Hu-Friedy Inc, Chicago, IL, USA). Number of the missing teeth was counted as well as the clinical attachment loss was calculated.

Dental plaque was measured on a scale of (0-3) [13] while, the amount of calculus deposits was assessed by the Calculus Surface Index (CSI) [14]. Pocket depth and gingival recession were measured at six sites per tooth (mesiobuccal, midbuccal, distobuccal, mesiolingual, midlingual, and distolingual) using the periodontal probe. Pocket depth was measured from the gingival margin to the lowest point at the base of the periodontal pocket while, the gingival recession was evaluated by measuring the distance from CEJ to the bottom of the periodontal pocket. Clinical attachment loss was measured in cases of exposure of (CEJ) by the distance from CEJ to base of the gingival sulcus. The level of CEJ was determined by tactile perception with the tip of the periodontal probe. In cases on which the (CEJ) was covered by calculus, hidden by a restoration or possibly lost due to wear or carious lesions. Accordingly, the location of such junction was estimated on the basis of the adjacent teeth [15]. Measurements of CAL were rounded off to the nearest millimeter. The mean value of the CAL was recorded and divided into 4 groups: $\mathrm{CAL}<1 \mathrm{~mm}$ (considered as normal group), CAL $\geq 1$ and $<3 \mathrm{~mm}$ (mild group), $\mathrm{CAL} \geq 3$ and $<5 \mathrm{~mm}$ (moderate group), and $\mathrm{CAL} \geq 5$ $\mathrm{mm}$ (severe group). According to age, the participants were divided into five groups: 25-34 years, 35-44 years, 45-54 years, 55-64 years, and $\geq 65$ years (Table 1).

Statistical analysis

Statistical analysis was performed using the risk factors as independent variables and CAL as a dependent variable. Significance of frequency of the risk factors among the participants was calculated using Chi-squared test. The categorical variables were expressed by proportions while the continuous variables were expressed as means. Multiple regression analysis was used to estimate the odds ratio of the independent variables associated with CAL. A P-value of 0.05 was considered significant.

\section{Result}

The descriptive data of the study population are summarized in Table 1. The study sample consisted of (884) participants with mean age $(38.13 \pm 11.75)$ ranged from 25 to 75 years. Males were $496(56.1 \%)$ with mean age $(39.06 \pm 12.42)$ years while, $388(43.9 \%)$ were females with mean age $(36.95 \pm 10.77)$ years. Out of the examined subjects, $255(28.8 \%)$ had CAL $<1 \mathrm{~mm}$ (normal group) and 657 (71.2\%) had CAL $\geq 1 \mathrm{~mm}$ (effected group) which was, according to the severity, categorized into three groups: 233 (26.4\%) participants had CAL $\geq 1$ and $<3 \mathrm{~mm}$ belongs to the mild group, 214 (24.2\%) participants had CAL $\geq 3$ and $<5$ $\mathrm{mm}$ belongs to the moderate group, and $182(20.6 \%)$ participants had CAL $\geq 5 \mathrm{~mm}$ belongs to the severe group.

Frequencies of the different levels of CAL associated with risk factors are summarized in Table 2. Findings of this study showed that the severity of CAL was increased with age progress with significant difference $(\mathrm{P}<0.05)$. Of the age group 25-34 years there were $47.9 \%$ subjects who had normal CAL $(1<\mathrm{mm})$ while only $3.2 \%$ of the age group $\geq$ 65 years was found with normal CAL. The relationship between the severity of CAL and the old ages as a risk factor was highly significant $(\mathrm{P}=0.000, \mathrm{OR}=1.27)$ (Table 3$)$.

Severity of attachment loss was observed more in males than in females with significant different $(P<0.05)$. Furthermore, the relationship between gender and CAL was significant $(\mathrm{P}=0.03, \mathrm{OR}=0.79)$.

Subjects who reported tooth brushing were much less than 
who did not use brushing (243 compared to 641). This directly reflected on their periodontal status as individuals who brushed their teeth were less effected with moderate and severe CAL $(8.2 \%, 2.5 \%)$ than those who did not $(30.3 \%, 27.5 \%)$ respectively with significant difference $(\mathrm{P}<0.05)$. The relationship between tooth brushing with $\mathrm{CAL}$ occurrence and severity was significant $(\mathrm{P}=0.001, \mathrm{OR}=0.80)$.

Out of the study sample $25.8 \%$ reported smoking while, $74.2 \%$ were non-smokers. Normal CAL was observed more among non-smokers than smokers $(36 \%, 3.8 \%)$ respectively with significant difference $(\mathrm{P}<0.05)$. Association between smoking with $\mathrm{CAL}$ severity was significant $(\mathrm{P}=0.02, \mathrm{OR}=$ 1.17).

Khat chewing was reported from $530(60 \%)$ respondents while, 354 (40\%) were non-khat chewers. Loss of attachment was higher among khat chewer than non-khat chewers in all CAL levels (mild, moderate, and sever) with significant difference. Significant relationship between khat chewing and CAL development and severity was found $(\mathrm{P}=0.02$, OR $=1.14$ ).

For plaque accumulation, the findings of the study found significant increasing in mean of plaque index with increasing severity of CAL. The mean of plaque was $(1.28 \pm 0.36)$ in normal subjects while, it ranged from 1.7 to 2.23 among effected subjects. Dental calculus was observed on $460(52 \%)$ subjects. Severity of CAL was significantly increased with the presence of calculus (Table 2). Significant relationship between dental plaque and calculus with $\mathrm{CAL}$ was found $(\mathrm{P}=0.000, \mathrm{OR}=1.82)$ and $(\mathrm{P}=0.000, \mathrm{OR}=$ 1.86) respectively (Table 3 ).

One of the main objectives of this study was to assess the role of teeth missing as a possible risk factor for attachment loss. The current study showed $30 \%$ of the study subjects had missed one or more of their teeth (Table 1). Furthermore, it was observed that the mean of the missing teeth was increased gradually among participants from normal basing through mild and moderate to the severe level of CAL $(0.05 \pm 0.64,0.6 \pm 1.43,1.47 \pm 2.28,4.18 \pm 4.07)$ respectively (Table 2). Moreover, significant relationship between teeth missing with $\mathrm{CAL}(\mathrm{P}=0.000, \mathrm{OR}=1.04)$ (Table 3$)$.

\section{Discussion}

The primary objectives in the present cross-sectional study were undertaken to assess the prevalence of clinical attachment loss and to determine some of the various risk factors of CAL in Yemeni adult population. The mild and moderate CAL in the present study were observed among $50.6 \%$ of the study population. These results were lower than those observed in previous studies conducted in South India (96.4\% had CAL $<5 \mathrm{~mm})$ [16], Korean (80.27\% had CAL < $5 \mathrm{~mm})$ [17], U.S.A $(32.7 \%$ had CAL $<5 \mathrm{~mm})$ [18], French (80.3\% had CAL $<5 \mathrm{~mm})$ [19], and Germany (89.7\% had $\mathrm{CAL}<5 \mathrm{~mm}$ ) [20], while the severe CAL was higher than those observed in the same above-mentioned studies.

High severity of CAL among Yemeni population might be related to the lower socioeconomic level and some social habits as Khat chewing. The various geographic regions which could be attributed to cultural traits, socioeconomic conditions, and habits of the target population might explain the variations of CAL prevalence in different populations worldwide [16].

In the present study, statistically significant relationship was observed between the risk factors evaluated with the mean of CAL. As illustrated in Table 2, increasing in prevalence and severity of CAL were accompanying with increasing in age. This result was similar to some of previous studies [17, 21, 22]. Furthermore, the relationship between the severity of CAL with age was highly significant $(\mathrm{P}=0.000, \mathrm{OR}=1.27)$. It has been documented that poorer oral hygiene with increasing age is related to an increase of exposure time to causative diseases and an increase in aging-related factors [24]. The findings of this study showed that males who had CAL $>5 \mathrm{~mm}$ were significantly higher than females. This result agreed with the results of some previous studies [16, 23]. Albandar [25] found, that the prevalence of periodontal probing depth $\geq 3 \mathrm{~mm}$ was 1.3 times higher in males and that $\geq 5 \mathrm{~mm}$ was 1.7 times higher in males. Females in the current study were 0.79 times less likely to have clinical attachment loss than males. These findings may be explained by the facts that females usually are more aesthetically conscious, thus would be more worried about visiting the dentist while, the males have poorer oral hygiene practices and less dental visit behaviors [26]. Severity of CAL was significantly higher among non-tooth brushing than subjects reported tooth brushing (27.5\% and $2.5 \%$ respectively). This result is in agreement with some previous studies indicating that a higher proportion of subjects who did not use tooth brushing had poor oral hygiene which had a significant association with pocket formation and the severity of CAL [27, 28]. Tooth brushing has a major role in periodontal health maintenance. Brushing reduces accumulation of dental plaque and in turn prevents gingivitis, periodontitis; whereas forceful, frequent and improper brushing technique may result in gingival recession and attachment loss [29].

Table 1. Characteristics and clinical records of all subjects.

\begin{tabular}{lll}
\hline Variable & Group & Number (\%) \\
\hline \multirow{4}{*}{ Age } & $25-34$ yrs & $405(45.8)$ \\
& $35-44$ yrs & $236(26.7)$ \\
& $45-54$ yrs & $134(15.2)$ \\
$55-64$ yrs & $78(8.8)$ \\
Gender & $\geq 65$ yrs & $31(3.5)$ \\
& Male & $496(56.1)$ \\
Brushing & Female & $388(43.9)$ \\
& No & $641(72.5)$ \\
Smoking & Yes & $243(27.5)$ \\
Khat chewing & No & $656(74.2)$ \\
& Yes & $228(25.8)$ \\
Missing Teeth & No & $354(40)$ \\
& Yes & $530(60)$ \\
Calculus Index & No & $617(70)$ \\
& Yes & $267(30)$ \\
& Not present & $424(48)$ \\
CAL & Present & $460(52)$ \\
& $<1 \mathrm{~mm}$ & $255(28.8)$ \\
& $1 \leq \mathrm{CAL}<3 \mathrm{~mm}$ & $233(26.4)$ \\
& $3 \leq \mathrm{CAL}<5 \mathrm{~mm}$ & $214(24.2)$ \\
& $\geq 5 \mathrm{~mm}$ & $182(20.6)$ \\
\hline
\end{tabular}


Among the participants in this study who reported smoking, $31.6 \%$ had moderate CAL and $36 \%$ had sever CAL while, non-smokers who had moderate and sever CAL were $21.6 \%$ and $15.2 \%$ respectively. Smokers are 1.17 times likely to have loss of attachment than non-smokers. These findings are in accordance with the results of previous studies [30, 31]. Numerous epidemiologic studies reported that smoking is a major risk factor for periodontal disease [32]. Furthermore, other previous study has indicated that, smoking is closely related to CAL [17]. This is might be related to the major role of smoking in development and provoking of periodontitis by affecting host immune responses [33].

Statistically significant increasing in severity of CAL was observed among Khat chewers than non-Khat chewers. Severity of CAL was 1.14 times more among Khat chewers.
The habit of khat chewing is widely spread among Yemeni population. Khat (Qat) plant (Catha edulis) is a tree belongs to family Celastraceous frequently cultivated in certain areas of East Africa and the Arabian Peninsula [34]. The findings of the current study are similar with previous studies reported that high rate of periodontal diseases have been observed among male Yemeni khat chewers $[35,36]$. In contrast, some reports [37, 38] demonstrated that khat chewing was associated with CAL but not pocket depth. Khat chewing appeared to be the most etiological factors causing the gingival recession resulting in $\mathrm{CAL}$ among Yemeni population [39]. Furthermore, Al-sharaby et al. [40], in a study conducted on Yemeni adult males, reported that heavy long-time khat chewing is probably an independent risk factor of clinical attachment loss.

Table 2. Frequencies of the different levels of CAL and risk factors.

\begin{tabular}{|c|c|c|c|c|c|c|c|}
\hline \multirow{3}{*}{ Variables } & & \multicolumn{4}{|c|}{ Clinical Attachment Loss } & \multirow{3}{*}{ Total } & \multirow{3}{*}{ P value } \\
\hline & & \multirow{2}{*}{$\begin{array}{l}\text { Normal } \\
<1 \mathrm{~mm}\end{array}$} & \multirow{2}{*}{$\begin{array}{l}\text { Mild } \\
1 \leq \mathrm{CAL}<3 \mathrm{~mm}\end{array}$} & \multirow{2}{*}{$\begin{array}{l}\text { Moderate } \\
3 \leq \mathrm{CAL}<5 \mathrm{~mm}\end{array}$} & \multirow{2}{*}{$\begin{array}{l}\text { Severe } \\
\geq 5 \mathrm{~mm}\end{array}$} & & \\
\hline & & & & & & & \\
\hline \multicolumn{7}{|l|}{ Age } & \multirow{6}{*}{$<.0001$} \\
\hline & $25-34$ yrs & $194(47.9)$ & $122(30.1)$ & $62(15.3)$ & $27(6.7)$ & $405(45.8)$ & \\
\hline & $35-44 \mathrm{yrs}$ & $49(20.8)$ & $73(30.9)$ & $69(29.2)$ & $45(19.1)$ & $236(26.7)$ & \\
\hline & $45-54$ yrs & $10(7.5)$ & $31(23.1)$ & $57(42.5)$ & $36(26.9)$ & $134(15.2)$ & \\
\hline & $55-64 \mathrm{yrs}$ & $1(1.3)$ & $4(5.1)$ & $19(24.4)$ & $54(69.2)$ & $78(8.8)$ & \\
\hline & $\geq 65 \mathrm{yrs}$ & $1(3.2)$ & $3(9.7)$ & $7(22.6)$ & $20(64.5)$ & $31(3.5)$ & \\
\hline \multicolumn{7}{|l|}{ Gender } & \multirow{3}{*}{$<.0001$} \\
\hline & Male & $116(23.4)$ & $137(27.6)$ & $120(24.2)$ & $123(24.8)$ & $496(56.1)$ & \\
\hline & Female & $139(35.8)$ & $96(24.7)$ & $94(24.2)$ & $59(15.2)$ & $388(43.9)$ & \\
\hline \multicolumn{7}{|l|}{ Brushing } & \multirow{3}{*}{$<.0001$} \\
\hline & No & $102(15.9)$ & $169(26.4)$ & $194(30.3)$ & $176(27.5)$ & $641(72.5)$ & \\
\hline & Yes & $153(63)$ & $64(26.3)$ & $20(8.2)$ & $6(2.5)$ & $243(27.5)$ & \\
\hline \multicolumn{7}{|l|}{ Smoking } & \multirow{3}{*}{$<.0001$} \\
\hline & No & $236(36)$ & $178(27.1)$ & $142(21.6)$ & $100(15.2)$ & $656(74.2)$ & \\
\hline & Yes & $19(8.3)$ & $55(24.1)$ & $72(31.6)$ & $82(36)$ & $228(25.8)$ & \\
\hline \multicolumn{7}{|c|}{ Khat chewing } & \multirow{3}{*}{$<.0001$} \\
\hline & No & $163(46)$ & $82(23.2)$ & $68(19.2)$ & $41(11.6)$ & $354(40)$ & \\
\hline & Yes & $92(17.4)$ & $151(28.5)$ & $146(27.5)$ & $141(26.6)$ & $530(60)$ & \\
\hline \multicolumn{7}{|l|}{ Calculus } & \multirow{3}{*}{$<.0001$} \\
\hline & Not present & $238(56.1)$ & $124(29.2)$ & $51(12)$ & $11(2.6)$ & $424(48)$ & \\
\hline & Present & $17(3.7)$ & $109(23.7)$ & $163(35.4)$ & $171(37.2)$ & $460(52)$ & \\
\hline \multicolumn{2}{|c|}{ Missing Teeth $(1.39 \pm 2.75)$} & $(0.05 \pm .64)$ & $(0.6 \pm 1.43)$ & $(1.47 \pm 2.28)$ & $(4.18 \pm 4.07)$ & $(0.05 \pm .64)$ & $<.0001$ \\
\hline \multicolumn{2}{|c|}{ Plaque Index $(1.746 \pm 0.51)$} & $(1.28 \pm .36)$ & $(1.7 \pm .37)$ & $(1.95 \pm .40)$ & $(2.23 \pm .38)$ & $(1.28 \pm .36)$ & $<.0001$ \\
\hline
\end{tabular}

Table 3. Multiple regression analysis with adjusted odds ratio.

\begin{tabular}{|c|c|c|c|c|c|c|}
\hline \multirow{2}{*}{ Variable } & \multirow{2}{*}{ Estimated Coefficient } & \multirow{2}{*}{ Std. Error } & \multirow{2}{*}{ Odds ratio } & \multirow{2}{*}{ Sig. } & \multicolumn{2}{|l|}{$95 \%$ CI } \\
\hline & & & & & Lower Bound & Upper Bound \\
\hline Age & 0.242 & 0.026 & 1.27 & 0.001 & 1.21 & 1.34 \\
\hline Gender & -0.422 & 0.057 & 0.79 & 0.027 & 0.66 & 0.98 \\
\hline Brushing & -0.217 & 0.064 & 0.8 & 0.001 & 0.71 & 0.91 \\
\hline Smoking & 0.155 & 0.065 & 1.17 & 0.016 & 1.03 & 1.33 \\
\hline Khat chewing & 0.13 & 0.057 & 1.14 & 0.022 & 1.02 & 1.27 \\
\hline Missing teeth & 0.043 & 0.011 & 1.04 & 0.001 & 1.02 & 1.07 \\
\hline Plaque Index & 0.599 & 0.067 & 1.82 & 0.001 & 1.6 & 2.07 \\
\hline Calculus Index & 0.621 & 0.063 & 1.86 & 0.001 & 1.64 & 2.1 \\
\hline
\end{tabular}

Dependent variable: Clinical Attachment Loss. ANOVA model: $\mathrm{P}<0.0001 . \mathrm{R}^{2}=0.629$ 
Plaque and calculus deposits were significantly associated with the severity of CAL. Subjects with plaque and calculus were 1.82 and 1.86 times respectively more likely to develop periodontal loss of attachment. These results are in accordance with the findings of Suresh Ranga Rao [16], López et al. [27], and De Souza and Taba [28] which reported that poor oral hygiene had a significant association with CAL severity. Plaque accumulation results in passage of bacteria and their products through the non-keratinized junctional epithelium leading to series of host responses that results in pocket formation and clinical attachment loss [41]. The result of this study showed that the mean of missing teeth was significantly higher among subjects who had moderate and severe CAL than individuals had mild CAL. The odds of CAL severity among subjects who have missing teeth were 1.04 times higher than the odds of CAL severity among subjects with no missing teeth. Numerous previous studies indicated that progression of periodontitis to the severe condition resulting in tooth loss by the destruction of tooth supporting tissues and loss of attachment [42, 43]. On the other hand, edentulous area without restoration for long time may lead to gingival recession and $\mathrm{CAL}$ on the adjacent teeth by continuous application of forces on that area during mastication. Moreover, non-tooth-supported removable partial dentures have adversely effects on the periodontium [44-46].

\section{Conclusion}

Within the limitations of this study it can be concluded that, a high prevalence of sever clinical attachment loss among adult Yemeni population. All risk factors mentioned in this study were strongly associated with the prevalence, extent, and severity of the periodontal attachment loss. Further studies with larger sample including adolescents and adult Yemeni population in different geographic areas are recommended.

\section{References}

[1] Haffajee AD, Socransky SS. Microbial etiological agents of destructive periodontal diseases. Periodontol 2000 1994; 5: 78-111.

[2] Brown LJ, Löe H. Prevalence, extent, severity and progression of periodontal disease. Periodontol 2000 1993; 2: 57-71.

[3] Fenesy KE. Periodontal disease: an overview for physicians. Mt Sinai J Med 1998; 65: 362-9.

[4] Kinane DF. Causation and pathogenesis of periodontal disease. Periodontol 2000 2001; 25: 8-20.

[5] Baelum V, Manji F, Wanzala P, Fejerskov O. Relationship between CPITN and periodontal attachment loss findings in an adult population. J Clin Periodontol 1995; 22: 146-52.

[6] Dye BA, Selwitz RH. The relationship between selected measures of periodontal status and demographic and behavioural risk factors. J Clin Periodontol 2005; 32: 798-808.

[7] Shaju Jacob P. Measuring periodontitis in population studies: a literature review. Rev Odonto Cienc 2011; 26: 346-354.
[8] Nunn ME. Understanding the etiology of periodontitis: an overview of periodontal risk factors. Periodontol 2000 2003; 32: $11-23$.

[9] Ali AA. Qat habit in Yemen society: a causative factor for oral periodontal diseases. Int J Environ Res Public Health. 2007; 4: 243-7.

[10] El-Angbawi MF, Younes SA. Periodontal disease prevalence and dental needs among school children in Saudi Arabia. Community Dent Oral Epidemiol 1982 10: 98-99.

[11] Fanas SH, Omer SM, Jaber M et al. The periodontal treatment needs of Libyan school children in Kufra and Tobruk. J Int Acad Periodontol 2008; 10: 45-49.

[12] Amran AG, Ataa MAS. Statistical analysis of the prevalence, severity and some possible etiologic factors of gingival recessions among the adult population of Thamar city, Yemen. RSBO (Online). 2011; 8: 305-13.

[13] Löe H, Silness J. Periodontal disease in pregnancy I. Prevalence and severity. Acta Odontol Scand 1963; 21: 53351 .

[14] Ainamo J, Bay I. Problems and proposals for recording gingivitis and plaque. Int Dent J 1975; 25: 229-35.

[15] Miller Jr PD. A classification of marginal tissue recession. Int J Periodontics Restorative Dent 1985; 5: 8-13.

[16] Rao SR, Thanikachalam S, Sathiyasekaran BWCS, Vamsi L, Balaji TM, and Jagannathan R. Prevalence and Risk Indicators for Attachment Loss in an Urban Population of South India: Oral Health Dent Manag 2014; 13: 60-4.

[17] Rheu GB, Ji S, Ryu JJ, Lee JB, Shin C, Sang-Wan Shin, JungBo Huh. Risk assessment for clinical attachment loss of periodontal tissue in Korean adults. J Adv Prosthodont. 2011; 3: 25-32.

[18] Dye BA, Tan S, Smith V, Lewis BG, Barker LK, ThorntonEvans G, Eke PI, Beltrán-Aguilar ED, Horowitz AM, Li CH. Trends in oral health status: United States, 1988-1994 and 1999-2004. Vital Health Stat 2007; 248: 1-92.

[19] Bouchard P, Boutouyrie P, Mattout C, Bourgeois D. Risk assessment for severe clinical attachment loss in an adult population. J Periodontol 2006; 77: 479-489.

[20] Holtfreter B, Schwahn C, Biffar R, Kocher T. Epidemiology of periodontal diseases in the Study of Health in Pomerania. $\mathrm{J}$ Clin Periodontol 2009; 36: 114-23.

[21] Khader YS, Rice JC, Lefante JJ. Factors associated with periodontal diseases in a dental teaching clinic population in northern Jordan. J Periodontol 2003; 74: 1610-1617.

[22] Tran DT, Gay I, Du XL, Fu Y, Bebermeyer RD, Neumann AS, Streckfus C, Chan W, Walji MF. Assessment of partial-mouth periodontal examination protocols for periodontitis surveillance. J Clin Periodontol. 2014; 41: 846-852.

[23] Susin C, Dalla Vecchia CF, Oppermann RV, Haugejorden O, Albandar JM. Periodontal attachment loss in an urban population of Brazilian adults: effect of demographic, behavioral, and environmental risk indicators. J Periodontol 2004; 75: 1033-41.

[24] Papapanou PN, Lindhe J, Sterrett JD, Eneroth L. Considerations on the contribution of ageing to loss of periodontal tissue support. J Clin Periodontol 1991; 18: 611-5. 
[25] Albandar JM. Global risk factors and risk indicators for periodontal diseases. Periodontol 2000 2002; 29: 177-206.

[26] Christensen LB, Petersen PE, Krustrup U, Kjoller M. Selfreported oral hygiene practices among adults in Denmark. Community Dent Health 2003; 20: 229-35.

[27] López R, Fernández O, Jara G, Baelum V. Epidemiology of clinical attachment loss in adolescents. J Periodontol 2001; 72: 1666-1674.

[28] De Souza SL and Taba M Jr. Cross-sectional evaluation of clinical parameters to select high prevalence populations for periodontal disease: the site comparative severity methodology. Braz Dent J 2004; 15: 46-53.

[29] Joshipura KJ, Kent RL, DePaola PF. Gingival recession: intraoral distribution and associated factors. J Periodontol 1994; 65: 864-871.

[30] Martinez-Canut P, Lorca A, Magán R. Smoking and periodontal disease severity. J Clin Periodontol 1995; 22: 743749.

[31] Haffajee AD, Socransky SS. Relationship of cigarette smoking to attachment level profiles. J Clin Periodontol 2001; 28: 283295.

[32] Borrell LN, Papapanou PN. Analytical epidemiology of periodontitis. J Clin Periodontol 2005; 32: 132-58.

[33] Palmer RM, Wilson RF, Hasan AS, Scott DA. Mechanisms of action of environmental factors-tobacco smoking. J Clin Periodontol 2005; 32: 180-95.

[34] Al-Hebshi N. N. and N. Skaug, "Khat (Catha edulis) - an updated review," Addict Biol 2005; 10: 299-307.

[35] Al-Motarreb A., K. Baker, and K. J. Broadley, "Khat: pharmacological and medical aspects and its social use in Yemen," Phytother Res 2002; 16: 403-413.

[36] Hassan N. A., Gunaid A. A., and I. M. Murray-Lyon, "Khat (Catha edulis): Health aspects of khat chewing," East. Mediterr. Health J 2007; 13: 706-718.
[37] Yarom N., J. Epstein, H. Levi, D. Porat, E. Kaufman, and M. Gorsky, "Oral manifestations of habitual khat chewing: a casecontrol study," Oral Surg Oral Med Oral Pathol Oral Radiol Endod 2010; 109: e60-e66.

[38] Mengel R., M. Eigenbrodt, T. Schunemann, and L. FloresdeJacoby, "Periodontal status of a subject sample of Yemen," J Clin Periodontol 1996; 23: 437-443.

[39] Amran AG, Ataa MAS. Statistical analysis of the prevalence, severity and some possible etiologic factors of gingival recessions among the adult population of Thamar city, Yemen. RSBO (Online). 2011; 8: 305-13.

[40] Al-Sharabi A. K., H. M. Shuga-Aldin, N. N. Al-Hebshi, andI. Ghandour. Qat Chewing as an Independent Risk Factor for Periodontitis: A Cross-Sectional Study: IJD Volume 2013, Article ID 317640, 7 pages.

[41] Cawson RA. Essentials of Dental Surgery and Pathology. London: Simon Fathers; 1991.

[42] Williams RC. Understanding and managing periodontal diseases: a notable past, a promising future. J Periodontol. 2008; 79 (8 Suppl): 1552-9.

[43] Botero JE, Rösing CK, Duque A, Jaramillo A, Contreras A. Periodontal disease in children and adolescents of Latin America. Periodontol 2000 2015; 67: 34-57.

[44] Wright PS, Hellyer PH. Gingival recession related to removable partial dentures in older patients. J Prosthet Dent 1995; 74: 602-7.

[45] Lee HJ, Garcia RI, Janket SJ, Jones JA, Mascarenhas AK, Scott TE, Nunn ME. The association between cumulative periodontal disease and stroke history in older adults. J Periodontol 2006; 77: 1744-54.

[46] Knezovic Zlataric D, Celebic A, Valentic-Peruzovic M. The effect of removable partial dentures on periodontal health of abutment and non-abutment teeth. J Periodontol 2002; 73: 137-44. 